Article

\title{
Low Cost, Multi-Pollutant Sensing System Using Raspberry Pi for Indoor Air Quality Monitoring
}

\author{
He Zhang ${ }^{1, *}$, Ravi Srinivasan ${ }^{1}$ and Vikram Ganesan ${ }^{2}$ \\ 1 UrbSys (Urban Building Energy, Sensing, Controls, Big Data Analysis, and Visualization) Laboratory, \\ M.E. Rinker, Sr. School of Construction Management, University of Florida, Gainesville, FL 32603, USA; \\ sravi@ufl.edu \\ 2 Department of Mechanical and Aerospace Engineering, Herbert Wertheim College of Engineering, \\ University of Florida, Gainesville, FL 32603, USA; vikram.ganesan@ufl.edu \\ * Correspondence: rupta00@ufl.edu
}

Citation: Zhang, H.; Srinivasan, R.;

Ganesan, V. Low Cost,

Multi-Pollutant Sensing System Using Raspberry Pi for Indoor Air Quality Monitoring. Sustainability 2021, 13, 370. https://doi.org/ $10.3390 /$ su13010370

Received: 12 November 2020 Accepted: 30 December 2020 Published: 3 January 2021

Publisher's Note: MDPI stays neutral with regard to jurisdictional clai$\mathrm{ms}$ in published maps and institutional affiliations.

Copyright: $(2021$ by the authors. Licensee MDPI, Basel, Switzerland. This article is an open access article distributed under the terms and conditions of the Creative Commons Attribution (CC BY) license (https:// creativecommons.org/licenses/by/ $4.0 /)$.

\begin{abstract}
Deteriorating levels of indoor air quality is a prominent environmental issue that results in long-lasting harmful effects on human health and wellbeing. A concurrent multi-parameter monitoring approach accounting for most crucial indoor pollutants is critical and essential. The challenges faced by existing conventional equipment in measuring multiple real-time pollutant concentrations include high cost, limited deployability, and detectability of only select pollutants. The aim of this paper is to present a comprehensive indoor air quality monitoring system using a low-cost Raspberry Pi-based air quality sensor module. The custom-built system measures 10 indoor environmental conditions including pollutants: temperature, relative humidity, Particulate Matter $(\mathrm{PM})_{2.5}, \mathrm{PM}_{10}$, Nitrogen dioxide $\left(\mathrm{NO}_{2}\right)$, Sulfur dioxide $\left(\mathrm{SO}_{2}\right)$, Carbon monoxide $(\mathrm{CO})$, Ozone $\left(\mathrm{O}_{3}\right)$, Carbon dioxide $\left(\mathrm{CO}_{2}\right)$, and Total Volatile Organic Compounds (TVOCs). A residential unit and an educational office building was selected and monitored over a span of seven days. The recorded mean $\mathrm{PM}_{2.5}$, and $\mathrm{PM}_{10}$ concentrations were significantly higher in the residential unit compared to the office building. The mean $\mathrm{NO}_{2}, \mathrm{SO}_{2}$, and TVOC concentrations were comparatively similar for both locations. Spearman rank-order analysis displayed a strong correlation between particulate matter and $\mathrm{SO}_{2}$ for both residential unit and the office building while the latter depicted strong temperature and humidity correlation with $\mathrm{O}_{3}, \mathrm{SO}_{2}, \mathrm{PM}_{2.5}$, and $\mathrm{PM}_{10}$ when compared to the former.
\end{abstract}

Keywords: indoor air quality; smart environment monitoring (SEM); sensors; raspberry Pi

\section{Introduction}

In the past decade, declining air quality has emerged as one of the largest global environmental issues due to its harmful effects on human health. The American Lung Association (ALA) "State of the Air ${ }^{\circledR} 2020$ " estimated that nearly $49 \%$ of the United States population lived in harmful environmental air conditions [1]. An average person spends upward of $90 \%$ of time indoors and owing to the COVID-19 pandemic, this percentage has further increased [2]. A total of 1.6 million premature deaths worldwide are attributed to indoor air pollution [3]. Harm inducing health conditions such as Sick Building Syndrome (SBS) and Building Related Illness (BRI) are proven to be the effects of unhealthy levels of indoor air quality [4-7]. According to the US Environmental Protection Agency (EPA), the major constituents of indoor air pollution include Particulate Matter (PM), Nitrogen dioxide $\left(\mathrm{NO}_{2}\right)$, Sulfur dioxide $\left(\mathrm{SO}_{2}\right)$, Carbon monoxide $(\mathrm{CO})$, Ozone $\left(\mathrm{O}_{3}\right)$, Carbon dioxide $\left(\mathrm{CO}_{2}\right)$, and Total Volatile Organic Compounds (TVOCs) [8]. Particulate Matter (PM) refers to a mixture of airborne particles, which are generally categorized by diameter as $\mathrm{PM}_{10}(2.5 \mu \mathrm{m}$ to $10 \mu \mathrm{m})$ and $\mathrm{PM}_{2.5}$ (less than $\left.2.5 \mu \mathrm{m}\right)[6,8,9]$. Fine particles of aerosol in the form of PM serve as means for viruses to propagate, causing various respiratory diseases. $\mathrm{NO}_{2}$ is a reddish-brown gas that is mainly generated by vehicular traffic in the outdoor environment, while indoors, it is caused by tobacco smoke and fuel-burning 
appliances $[6,8,10,11]$. The highly reactive $\mathrm{SO}_{2}$ is the most harmful gas among the family of Sulfur oxides $\left(\mathrm{SO}_{\mathbf{x}}\right)[8,12,13]$. The most common source of $\mathrm{SO}_{2}$ is the combustion of fossil fuels and it results in respiratory illness and throat irritation. $\mathrm{CO}_{2}$ is mainly generated by human-activity and incomplete combustion of organic compounds. Increasing levels of this gaseous pollutant may cause headaches, drowsiness, and fatigue $[8,14,15]$. Although $\mathrm{CO}_{2}$ is not a pollutant per se, it can be used to determine ventilation rates which affect indoor air quality. The common sources of $\mathrm{CO}$, which is a toxic gaseous pollutant, are gas-type space and water heaters, fuel-burning appliances, tobacco smoke, and vehicle emissions. This colorless, odorless gas results in cardiovascular diseases, chest pain, nausea, fatigue, and asthma [8,16-18]. Ground-level $\mathrm{O}_{3}$ is the product of volatile organic compounds and nitrogen oxides reacting in the presence of ambient air and solar radiation [11,19]. The source of these reactants includes traffic emissions, electric utilities, while high amounts of heat sources such as volcanic eruptions can act as a catalyst to expedite the reaction to form increased amounts of $\mathrm{O}_{3}[8,20]$. TVOC is a collection of multiple harmful organic compounds that arises from household products, building materials, and human-activities such as smoking and cooking. Some of the common health impacts of ground-level ozone are pulmonary diseases, throat infection, coughing, and wheezing [4,8,21].

The air pollutants mentioned above serve as key parameters to indicate air quality, and to ensure safe, habitable environmental conditions, they are monitored periodically. The well-established air quality stations provide city-scale approximations of outdoor air pollutant concentrations, while air quality monitors can be used for smaller regions to gather data locally (both indoor and outdoor) $[8,22,23]$. In addition, due to a developing semi-conductor market in recent times, multiple off-the-shelf Low-Cost Air Quality Sensors (LCAQSs) are available, which may be used to gather reliable, real-time indoor air quality estimations. While the traditional monitors utilizing the federal reference method (FRM) or federal equivalent method (FEM) cost more than thousands of dollars, these low-cost alternative sensors are priced at a few hundred dollars and offer added advantages of easier installation and transmissions, variable time-interval recording options, and convenient data extraction [8,24-26]. The LCAQS technology is an open platform communications (OPC) system, which integrates electrical conductivity (EC) sensors and non-dispersive infrared (NDIR) sensors with a metal-oxide-semiconductor (MOS) module [8,27]. A PID (Proportional-Integral-Derivative) controller is used to control the operations of the system. The technology is open-source in nature and can be interfaced with already existing programmable circuit boards and Internet of Things (IoT) platforms. However, to evaluate the performance and effectiveness of LCAQS against traditional monitors, there is a lack of a standard protocol $[8,24,27]$. The data collected by these LCAQS systems are subjected to both field and laboratory testing by the AQ-SPEC governed by the EPA to ensure an acceptable level of data accuracy and stability is met $[8,26,28]$. The specification sheet for these LCAQSs lacks a calibration protocol, and the end-users depend on the factory-calibrated settings for data monitoring. Also, inter-pollutant sensitivity leads to uncertainties in measurements among most of the gaseous LCAQSs. Compared to the expensive air quality monitors, the operational lifespan of existing LCQASs is shorter [23,27,29-31].

In recent years, the concept of using a single-board computer (SCB) powered LCAQS to measure indoor air pollutants has surged. The Arduino electronic board powered Indoor Air Quality (IAQ) monitoring system built by S. Abraham and X. Li [32] measured pollutants such as $\mathrm{CO}_{2}, \mathrm{CO}$, and VOCs to determine air quality. A wireless data transfer technology was set up using a ZigBee module, and the collected data is compared against an off-the-shelf GreyWolf monitor. Zhou et al. [33] developed a monitoring system using Arduino Leonardo, which gathers longitudinal data of dust (PM2.5), temperature, and humidity to alert the user towards an unhealthy air quality. The Internet of Things (IoT) technology is utilized to transmit the measured pollutant concentrations to an online dashboard to visualize and post-process the data. Similar to Arduino, the Raspberry Pi is a versatile SCB which can be integrated with a wireless sensor network (WSN) to determine air quality [34]. Studies have shown that air pollutant concentrations are measured by 
attaching multiple gas sensors to a Raspberry Pi board [34-38]. The measured data can be visualized in real-time and also extracted remotely using a local network by the end-user. The Open Source Building Science Sensors (OSBSS) platform developed by Akram et al. provides a low-cost Arduino-based system for monitoring and recording long-term indoor parameters such as light and $\mathrm{CO}_{2}$ [39]. Thomas, Alex, and Richard (2019) [40] analyzed the calibration data of 100 air quality monitoring devices from 24 office building to measure the accuracy of monitors using the Monte Carlo simulation. The existing LCAQS studies primarily focus on pollutants such as PM2.5, $\mathrm{CO}_{2}$, and PM10 more frequently than CO, Ozone, and $\mathrm{NO}_{2}$, while $\mathrm{SO}_{2}$ and TVOC are rarely encountered [8,41,42].

The aim of this paper is to present a comprehensive indoor air quality monitoring system using a low-cost Raspberry Pi-based air quality sensor module. The proposed system measures environmental parameters such as temperature, relative humidity, $\mathrm{PM}_{2.5}, \mathrm{PM}_{10}$, $\mathrm{NO}_{2}, \mathrm{SO}_{2}, \mathrm{CO}_{2}, \mathrm{CO}, \mathrm{O}_{3}$, and TVOC in real-time to determine air quality. The remainder of this paper is structured as follows. Section 2 (materials and methods) describes the LCAQS system with its constituent sensors. The monitoring methods and different data analysis techniques employed are also detailed. Section 3 (results and discussions) presents a case study where the monitored data and results are discussed. The conclusion highlights the paper's contributions and possible future work in Section 4.

\section{Low Cost Air Quality System}

The custom built LCAQS monitoring system used for this project was developed on a Raspberry Pi 3B Plus module. This module is a low-power, compact, easily configurable SBC which is powered by an ARM Cortex-A53 processor [43]. The Raspberry Pi module encompasses features such as a Micro SD port for external storage access, Bluetooth, wireless LAN, USB ports, and GPIO pins for external communication. A nine-port expansion board was integrated into the Raspberry Pi module. A Wi-Fi USB adapter was connected to the Gigabit Ethernet port to establish access to the internet. In order to dissipate excess operational heat, a dual fan and heat sink module was attached to the Raspberry Pi system. Figure 1 shows the custom-built LCAQS monitoring system, and Figure 2 depicts a detailed block diagram with all electrical connections. The sensors used in this study were selected from the author's previous publication [8] accounting for repeatability, tolerance, and response time.

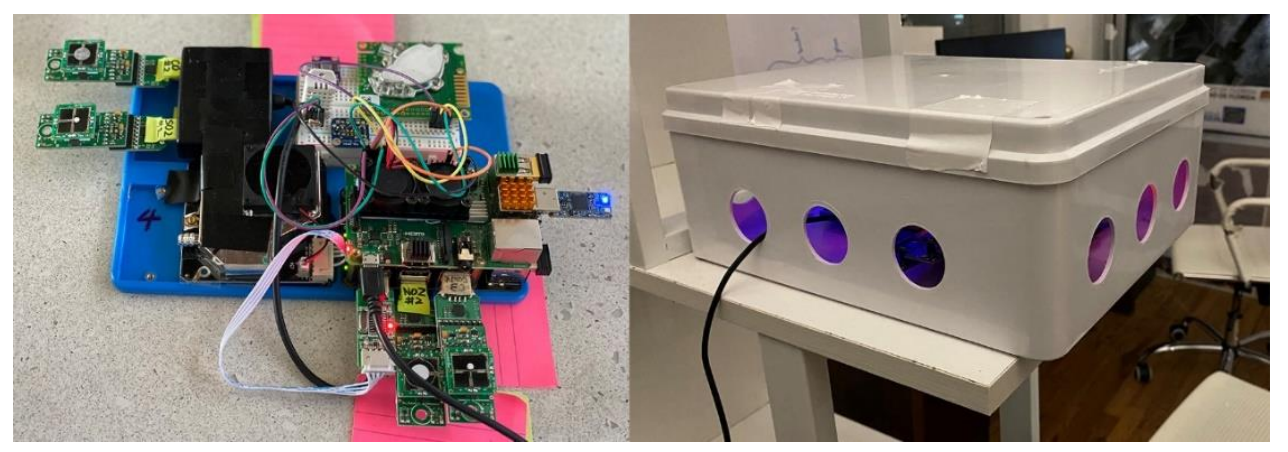

Figure 1. Custom built Low-Cost Air Quality Sensor (LCAQS) monitoring system placed inside a weather proof enclosure.

The DHT22 sensor is utilized to measure humidity and temperature levels. The sensor is connected to the Raspberry Pi module through a 5k pull-up resistor using I/O pins. The measuring capacity of the sensor ranges between $-40^{\circ} \mathrm{F}$ and $176^{\circ} \mathrm{F}$ with $\pm 0.5^{\circ} \mathrm{F}$ accuracy for temperature and from $0 \%$ to $100 \%$ with $\pm 2-5 \%$ accuracy or humidity [44]. DHT22 outputs humidity and temperature values as serial data. The SDS 011 sensor measures particulate matter between 0.3 and $10 \mu \mathrm{m}$ in diameter using a laser scattering technique. The sensor with a built-in fan is interfaced with the Raspberry Pi module using an UART (universal asynchronous receiver-transmitter) connection. SDS 011 with a 
quick response time $(<10 \mathrm{~s})$ can measure particulate matter concentrations between 0 and $999 \mu \mathrm{g} / \mathrm{m}^{3}$ with $\pm 15 \%$ accuracy [45]. $\mathrm{PM}_{2.5}$ and $\mathrm{PM}_{10}$ are outputted in the form of PWM (Pulse Width Modulation) output.

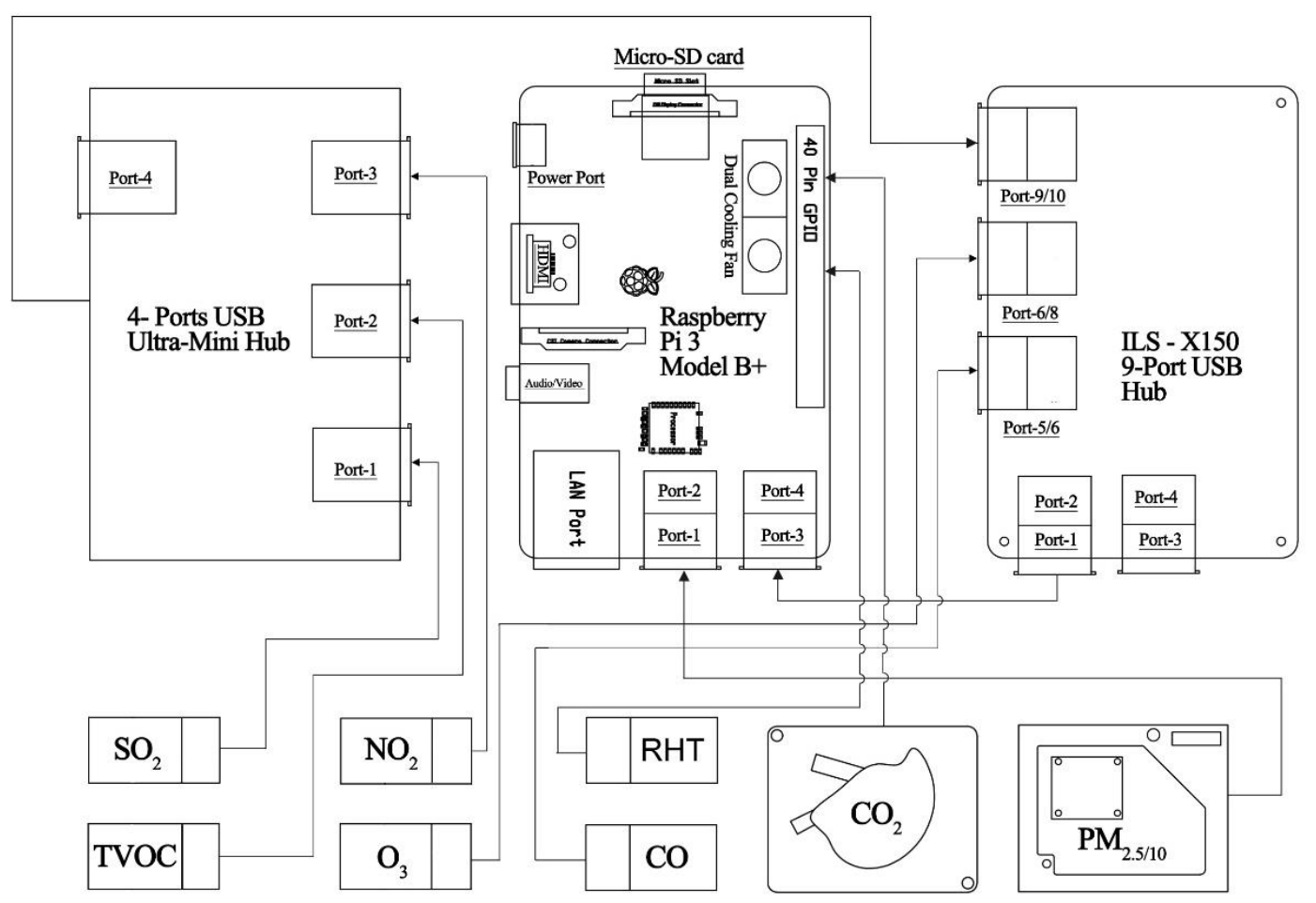

Figure 2. Detailed block diagram of the LCAQS monitoring system.

The SPEC-DGS-NO2 968-043 is a low-power IoT integrated gas sensor used to measure $\mathrm{NO}_{2}$ levels. The sensor with a circuit voltage of 3 volts is interfaced with the Raspberry Pi module using an UART connection. DGS-NO2-968-043, with a response time of fewer than $30 \mathrm{~s}$ and repeatability less than $\pm 3 \%$ of the reading, can measure $\mathrm{NO}_{2}$ concentrations between 0 and 5 ppm [46]. The SPEC-DGS-SO2-968-038 is a high-performance IoT integrated gas sensor used to measure $\mathrm{SO}_{2}$ levels. The sensor with a circuit voltage of 3 volts is interfaced with the Raspberry Pi module using an UART connection. DGS-SO2 968-038 with a response time of less than $30 \mathrm{~s}$ and repeatability less than $\pm 3 \%$ of the reading can measure $\mathrm{SO}_{2}$ concentrations between 0 and 20 ppm [47]. The Senseair K30 is an OEM (original equipment manufacturer) module which is customized as a sensor platform to measure $\mathrm{CO}_{2}$ gas. The sensor uses the NDIR (non-dispersive infrared) technique to detect $\mathrm{CO}_{2}$ levels in a region. The module is interfaced with Raspberry Pi using an UART connection. SenseAir K30, with a quick response time of $20 \mathrm{~s}$, can measure $\mathrm{CO}_{2}$ concentrations between 0 and $5000 \mathrm{ppm}$ with accuracy of $\pm 3 \%$ of the reading [48]. The SPEC-DGS-CO 968-034 is a lightweight IoT integrated gas sensor used to measure $\mathrm{CO}$ levels. The sensor with a circuit voltage of 3.3 volts is interfaced with the Raspberry Pi module using an UART connection. DGS-CO-968-034 with a typical response time of $15 \mathrm{~s}$ and repeatability less than $\pm 3 \%$ of the reading (or $2 \mathrm{ppm}$, whichever is greater) can measure $\mathrm{CO}$ concentrations between 0 and $1000 \mathrm{ppm}$ [49]. The SPEC-DGS-O3-968-042 is an ultra-low power consumption IoT integrated gas sensor used to measure $\mathrm{O}_{3}$ levels. The sensor with a circuit voltage of 3.3 volts is interfaced with the Raspberry Pi module using an UART connection. DGS-O3-968042 with a response time of less than $30 \mathrm{~s}$ and repeatability less than $\pm 3 \%$ of the reading can measure $\mathrm{O}_{3}$ concentrations between 0 and 5 ppm [50]. The uThing:: $\mathrm{VOC}^{\mathrm{TM}}$ is an open access USB module which utilizes the Bosch BME680 air quality sensor to detect VOCs (volatile organic compounds) [51]. The BME680 sensor mainly detects compounds such as ethane, ethanol, acetone, and isoprene with an accuracy of $5 \%$. The module is integrated 
with Raspberry Pi using a simple USB connection, and the VCP (virtual communication port) interface is utilized to export data as a CSV (comma-separated values) file. The sensor with a response time of less than one second outputs an IAQ index between 0 and 500 based on EPA guidelines, which corresponds to the VOC concentrations [51]. The specifications and the market price of this LCAQS are shown in Table 1. Based on the official datasheets and specifications, the sensor modules chosen for this LCAQS are pre-calibrated in the factory with FRM/FEM equipment and therefore required no end-user calibration.

Table 1. Specifications of sensors used in the LCAQS system.

\begin{tabular}{|c|c|c|c|c|c|}
\hline $\begin{array}{l}\text { Measured } \\
\text { Parameter }\end{array}$ & Example Product & Manufacturer & Measuring Range & $\begin{array}{c}\text { Accuracy } \\
\text { (Repeatability) }\end{array}$ & $\begin{array}{l}\text { Approx. Price } \\
\text { (USD). } 2019\end{array}$ \\
\hline RHT & DHT22 & Aosong Electronics & $\begin{array}{l}40{ }^{\circ} \mathrm{C}-80{ }^{\circ} \mathrm{C} ; \\
0 \% \text { to } 100 \%\end{array}$ & $\pm 0.5^{\circ} \mathrm{C} ; \pm 1 \%$ & $\leq \$ 10$ \\
\hline $\mathrm{PM}_{2.5 / 10}$ & SDS011 & Nova Fitness & $0.0-999.9 \mu \mathrm{g} / \mathrm{m}^{3}$ & $15 \% ; \pm 10 \mu \mathrm{g} / \mathrm{m}^{3}$ & $\leq \$ 30$ \\
\hline $\mathrm{NO}_{2}$ & DGS-NO2 968-043 & SPEC Sensors & 0-10 ppm & $\pm 15 \%$ & $\leq \$ 75$ \\
\hline $\mathrm{SO}_{2}$ & DGS-SO2 968-038 & SPEC Sensors & 0-20 ppm & $\pm 15 \%$ & $\leq \$ 75$ \\
\hline $\mathrm{CO}_{2}$ & K-30 & CO2Meter & 0-5000 ppm & $\pm 30 \%$ & $\leq \$ 80$ \\
\hline $\mathrm{CO}$ & DGS-CO 968-034 & SPEC Sensors & 0-1000 ppm & $\pm 15 \%$ & $\leq \$ 75$ \\
\hline Ozone & DGS-O3 968-042 & SPEC Sensors & $0-5 \mathrm{ppm}$ & $\pm 15 \%$ & $\leq \$ 75$ \\
\hline TVOC & uThing:VOC ${ }^{\mathrm{TM}}$ & Ohmetech.io & 0-500 IAQ index & $\pm 15 \%$ & $\leq \$ 95$ \\
\hline
\end{tabular}

\section{Measurements Using LCAQS}

\subsection{Site-Description}

The two sites (Figure 3) chosen for this experiment were a university lab building and the living room of a two-bedroom residential apartment unit, both located in the city of Gainesville, Florida, United States. Gainesville is an inland city located in Alachua County of Central Florida, which experiences a humid subtropical climate all year-round. The lab building is an educational office space with a plywood floored area of 321 sq.ft situated at a distance of $245 \mathrm{ft}$ from the nearest major road. A 1.5-ton ducted split-type indoor air conditioning unit (Mitsubishi PEA-A18AA) provides centralized cooling for the room while the air handling unit maintains a constant airflow rate of 235 CFM [52]. This HVAC unit is coupled with a washable MERV-8 air filter with a $\mathrm{PM}_{2.5}$ removal efficiency of 20-35\% [53]. The mechanically ventilated space has three operable windows, which are closed at all times. Due to the COVID pandemic, the occupancy capacity is limited to a maximum of three people at a given time. The living room is part of a standard twobedroom residential unit. The unit is located on the second floor of a three-story building with a carpet floor area of 421 sq.ft. A 4-ton centralized air conditioning unit (GOODMAN GSX13048-AWUF24051BA) provides cooling, and the air handling unit maintains a constant airflow rate of 835 CFM [54]. This HVAC unit is coupled with a MERV-8 air filter with a $\mathrm{PM}_{2.5}$ removal efficiency of 20-35\% [53]. The mechanically ventilated space has two operable windows, which are closed at all times. The occupancy capacity is limited to a maximum of three people throughout the year. The distance between the two experimental sites is $2272.30 \mathrm{ft}$. The air conditioning units at both sites continuously function throughout the year. The experimental sites were chosen to study variations in air quality among two similar spaces with different functional purposes.

\subsection{Measuring and Sampling Methods}

Two distinct time periods spanning seven days were selected to conduct the experiments at the two respective locations. For the residential unit, data were collected between 8 September 2020 and 14 September 2020 while for the educational building, air quality was monitored from 17 September 2020 to 23 September 2020. In total, the 10 air quality 
parameters measured were relative humidity, temperature, $\mathrm{PM}_{2.5}, \mathrm{PM}_{10}, \mathrm{NO}_{2}, \mathrm{SO}_{2}, \mathrm{CO}_{2}$, $\mathrm{CO}, \mathrm{O}_{3}$, and TVOC. In order to structure the monitoring process to limit measurement uncertainties, the standardized EPA monitoring protocol for indoor air quality was implemented [10]. The ASHRAE 62.1-2019 standard was utilized for analyzing each air pollutant concentration [55]. In both monitoring locations, the LCAQS system was placed 3.7 feet above floor level, 1.5 feet away from a wall, and at least a 4.8 feet distance from any corner. Each of the two LCAQS systems deployed at both locations collects $24-\mathrm{h}$ continuous data in intervals of 10-min for all of the pollutants mentioned [10,27,56,57].

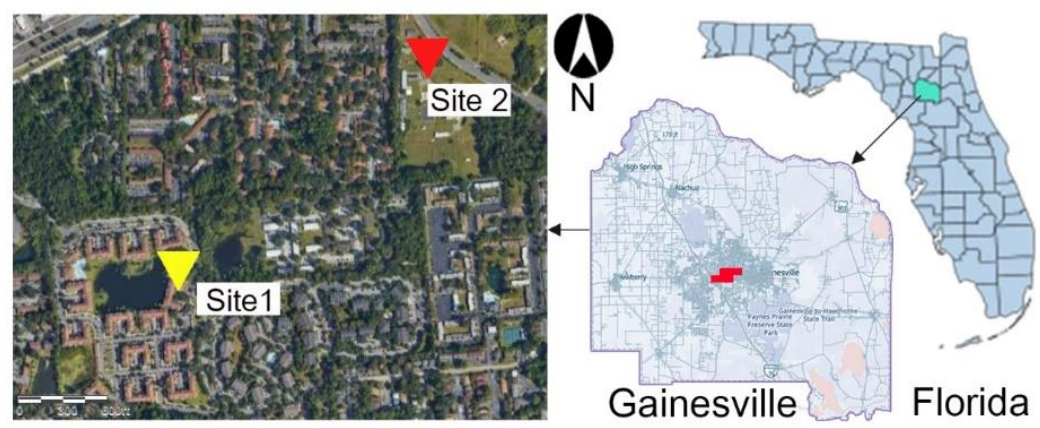

Figure 3. Geographical map of Gainesville city located in the state of Florida depicting monitoring locations site1(residential apartment unit) and site2 (educational office space).

\subsection{Data Analysis}

The data measured by the LCQAS systems are extracted and subjected to statistical analyses to understand the effects of indoor pollutant concentrations on air quality. Python (version 3.6.12) language was used to conduct descriptive analysis to determine statistical parameters such as mean, standard deviation, and variance. A quantile-quantile (Q-Q) plot was produced in Python to study the distribution pattern of the data set. Correlation studies were carried out in RStudio software (version 1.3.1093) to study the inter-dependency and influence of one pollutant on another. The monotonic relationship between pollutants was determined using Spearman rank-order correlation. The Spearman correlation coefficient ranging between -1 and 1 was utilized to establish a degree of correlation within pollutants, while a minimum sensitivity of $<0.05$ was considered significant [58-60].

\section{Results and Discussion}

The custom-built LCAQS system was deployed in two locations, namely: site 1 (a living room within a residential apartment unit) and site 2 (an educational office space). The system successfully gathered concurrent data from all of the individual sensor modules without hindrance at both respective locations. The values of monitored pollutants were extracted from the LCAQS system and transferred to an external computer without data attenuation.

Table 2 shows the monitored average environmental parameters along with its standard deviation, minimum, and maximum levels. Site 1 has a mean temperature and humidity of $80.5^{\circ} \mathrm{F}$ and $45.5 \%$, while site 2 has a relatively lower mean temperature of $75.5^{\circ} \mathrm{F}$ and a higher mean humidity of $70.4 \%$. The $\mathrm{PM}_{2.5}$ and $\mathrm{PM}_{10}$ concentrations for site one range between 0.20 and $50.5 \mu \mathrm{g} / \mathrm{m}^{3}$ and 0.20 and $80.9 \mu \mathrm{g} / \mathrm{m}^{3}$ while recording mean values of 8.53 and $10.2 \mu \mathrm{g} / \mathrm{m}^{3}$, respectively. The average $\mathrm{PM}_{2.5}$ and $\mathrm{PM}_{10}$ concentrations for site 2 are comparatively lower at 2.33 and $2.43 \mu \mathrm{g} / \mathrm{m}^{3}$. The mean $\mathrm{NO}_{2}$ concentration for site 2 at $60.3 \mathrm{ppb}$ is relatively higher than that of site 1 at $41.8 \mathrm{ppb}$, and the corresponding standard deviation follows a similar trend at 2.02 for site 1 and 6.94 for site 2 . Site 1 has a mean $\mathrm{SO}_{2}$ value of $39.9 \mathrm{ppb}$, while site 2 has a relatively lower value of $29.6 \mathrm{ppb}$. The minimum $\mathrm{CO}_{2}$ concentration of $761 \mathrm{ppm}$ recorded at site 1 is greater than the maximum value of 522 ppm registered at site 2. Similarly, the mean concentration of $2195 \mathrm{ppm}$ at site 1 is significantly higher than the mean value of $432 \mathrm{ppm}$ at site 2 . Since the collected CO 
data for site 2 was mostly negligible in value, it was deemed as statistically insignificant for this study. For site 1, the average $\mathrm{CO}$ concentration is $1.05 \mathrm{ppb}$, and the maximum value recorded is $2.12 \mathrm{ppb}$. The mean ozone level for site 1 at $12.1 \mathrm{ppb}$ is over five times greater than the mean concentration of $2.37 \mathrm{ppb}$ registered at site 2 . The recorded TVOC values were measured against the IAQ index scale ranging from 0 to 500. Site 1 has an average TVOC level of 139.2, and site 2 has a value of 121 while the maximum value for both sites is 250 .

Table 2. Descriptive statistics of indoor environmental parameters measured at site 1 and site 2 .

\begin{tabular}{|c|c|c|c|c|c|c|c|c|}
\hline & Site 1 & & & & Site 2 & & & \\
\hline Environmental Parameters & Average \pm SD & Min & $\operatorname{Max}$ & Median & Average \pm SD & Min & Max & Median \\
\hline $\mathrm{PM}_{2.5}\left(\mu \mathrm{g} / \mathrm{m}^{3}\right)$ & $8.53 \pm 11.9$ & 0.20 & 50.5 & 3.60 & $2.33 \pm 2.74$ & 0.00 & 13.8 & 1.20 \\
\hline $\mathrm{PM}_{10}\left(\mu \mathrm{g} / \mathrm{m}^{3}\right)$ & $10.2 \pm 16.1$ & 0.20 & 80.9 & 3.90 & $2.43 \pm 2.84$ & 0.00 & 14.3 & 1.30 \\
\hline $\mathrm{NO}_{2}(\mathrm{ppb})$ & $41.8 \pm 2.02$ & 34.1 & 53.5 & 41.8 & $60.3 \pm 6.94$ & 43.8 & 132 & 62.1 \\
\hline $\mathrm{SO}_{2}(\mathrm{ppb})$ & $39.9 \pm 20.7$ & 0.01 & 161 & 37.6 & $29.6 \pm 23.0$ & 4.79 & 114 & 22.6 \\
\hline $\mathrm{CO}_{2}(\mathrm{ppm})$ & $2195 \pm 479$ & 761 & 3039 & 2270 & $432 \pm 34.6$ & 384 & 522 & 424 \\
\hline $\mathrm{CO}(\mathrm{ppb})$ & $1.05 \pm 0.45$ & 0.00 & 2.12 & 1.06 & $\mathrm{~N} / \mathrm{A}$ & $\mathrm{N} / \mathrm{A}$ & $\mathrm{N} / \mathrm{A}$ & $\mathrm{N} / \mathrm{A}$ \\
\hline Ozone (ppb) & $12.1 \pm 1.84$ & 9.10 & 19.1 & 11.9 & $2.37 \pm 2.92$ & 0.00 & 23.7 & 1.65 \\
\hline TVOC & $139.2 \pm 68.2$ & 23.0 & 250 & 146 & $121 \pm 67.1$ & 25 & 250 & 123 \\
\hline Temp. $\left({ }^{\circ} \mathrm{F}\right)$ & $80.5 \pm 0.73$ & 76.6 & 81.7 & 80.7 & $75.5 \pm 1.20$ & 72.3 & 78.8 & 75.1 \\
\hline Humidity (\%) & $45.5 \pm 1.61$ & 44.3 & 62.8 & 54.5 & $70.4 \pm 3.28$ & 59.7 & 81.1 & 71.5 \\
\hline
\end{tabular}

The $\mathrm{PM}_{2.5}$ and $\mathrm{PM}_{10}$ concentrations follow a similar pattern for both site 1 and site 2 as plotted in Figure 4c,d. For the first three days, distinctive peaks varying in amplitudes are visible around midday for the particulate matter at Sites 1 and 2 . The crests with higher values at site 1 can be attributed to scheduled cooking activities when compared to relatively shorter peaks at site 2 , which may be due to increased human activity during lunch breaks and increased nearby vehicular traffic. These peaks can be compared against the ASHRAE 62.1-2019 standard for the particulate matter, which is $35 \mu \mathrm{g} / \mathrm{m}^{3}(24 \mathrm{~h})$ for $\mathrm{PM}_{2.5}$ and $150 \mu \mathrm{g} / \mathrm{m}^{3}(24 \mathrm{~h})$ for $\mathrm{PM}_{10}$. Some of the data points for $\mathrm{PM}_{2.5}$ exceed the ASHRAE 62.1-2019 [55] standard during mid-day, while PM $_{10}$ exclusively lies below the standard. On the latter half of the fifth day, a spike is detected starting in the late evening. This anomaly might be due to an organized house event containing three people, subsequently leading to increased house activity. This event can also be viewed in terms of increased pollutant concentrations simultaneously across $\mathrm{PM}_{10}, \mathrm{CO}_{2}, \mathrm{SO}_{2}$, and TVOC. From Figure $4 \mathrm{e}$, the $\mathrm{NO}_{2}$ concentrations for site 1 show a significantly stable pattern across the seven-day monitoring period. The potential reason for this trend could be the lack of $\mathrm{NO}_{2}$ emitting sources. The recurring smooth crests for site 2 can be attributed to a gradual increase in traffic-related pollution over the course of the day peaking at midday. The ASHRAE 62.1-2019 standard for $\mathrm{NO}_{2}$ is $100 \mathrm{ppb}(1 \mathrm{~h})$, and at both sites the $\mathrm{NO}_{2}$ levels recorded are below this standard. The $\mathrm{SO}_{2}$ concentrations follow a relatively similar trend for both site 1 and site 2, as plotted in Figure 4f. The ASHRAE 62.1-2019 standard for $\mathrm{SO}_{2}$ is $75 \mathrm{ppb}(1 \mathrm{~h})$, and at both sites, some data points recorded oscillate above this standard. The $\mathrm{CO}_{2}$ concentrations for site 2 show a significantly low value exhibiting a stable pattern across the span of seven-days, as viewed in Figure $4 \mathrm{~g}$. The potential reason for this trend could be because of increased sedentary human behavior within the office space. The ASHRAE 62.1-2019 standard for $\mathrm{CO}_{2}$ is $1000 \mathrm{ppm}(24 \mathrm{~h})$, and at site 2, the $\mathrm{CO}_{2}$ levels registered are below this standard. Most of the data points are above the standard for Site 1, which might be due to factors such as $\mathrm{CO}_{2}$ exhalation from increased people count, cooking, and emissions from household cleaning products. The CO concentrations detected in site 1 portray a relatively low value when compared to the ASHRAE 62.1-2019 standard for $\mathrm{CO}$, which is $9 \mathrm{ppm}(8 \mathrm{~h})$. Figure $4 \mathrm{i}$ shows $\mathrm{O}_{3}$ concentrations where site 1 displays a significantly stable pattern across the entirety of the study period. The possible reason for this trend could be a lack of nearby vehicular-emissions, which is a primary source of 
ground-level $\mathrm{O}_{3}$. The repeating low-amplitude smooth peaks for site 2 can be attributed to locational proximity to traffic-related pollution over the course of the day. Both sites recorded $\mathrm{O}_{3}$ levels below the ASHRAE 62.1-2019 standard of $70 \mathrm{ppb}(8 \mathrm{~h})$. The measured TVOC data is mapped onto the IAQ index scale, which classifies air quality on a scale of 0 to 500 as: good (0-50), average (51-100), little bad (101-150), bad (151-200), worse (201-300), and very bad (301-500) [51,61]. As depicted in Figure 4j, the data oscillates, leaving only a few observation points below the acceptable good standard, and some even exceed the worse standard line. Both sites display TVOC concentrations that peak at varying amplitudes throughout the study period around midday. The only exception is day five at site 2 where the decline in TVOC levels can be attributed to the absence of occupants. This decline in concentration is also simultaneously seen in $\mathrm{PM}_{2.5}, \mathrm{PM}_{10}$, and $\mathrm{O}_{3}$.

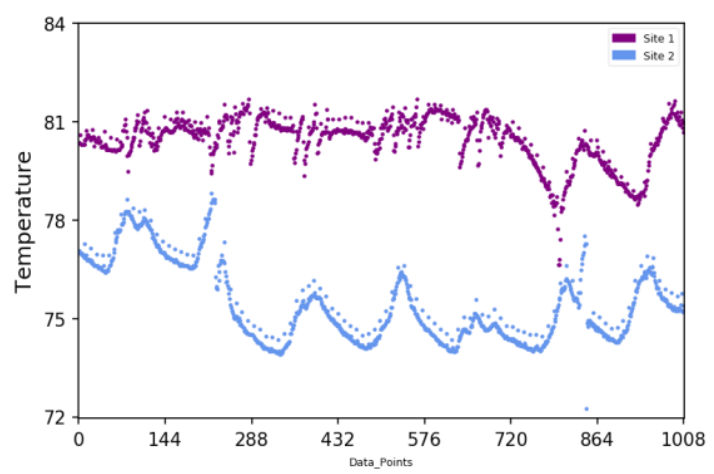

(a)

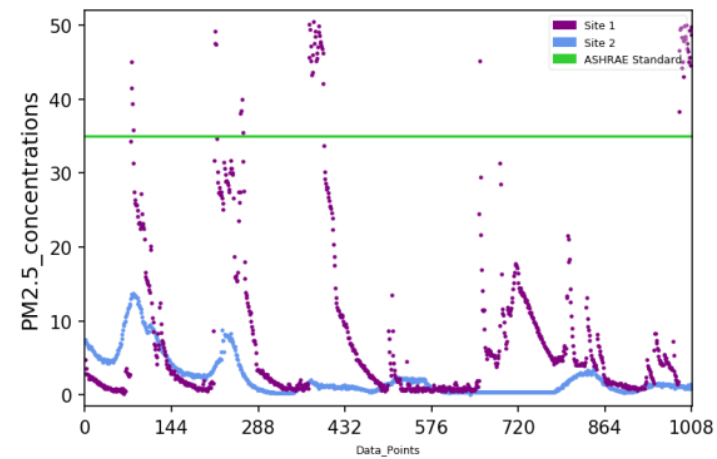

(c)

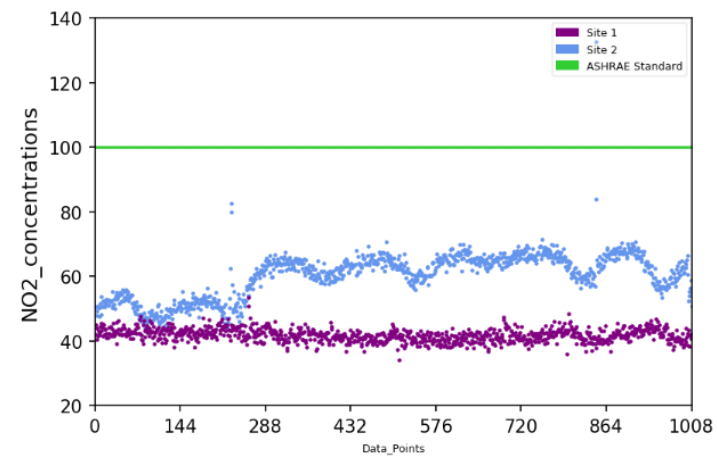

(e)

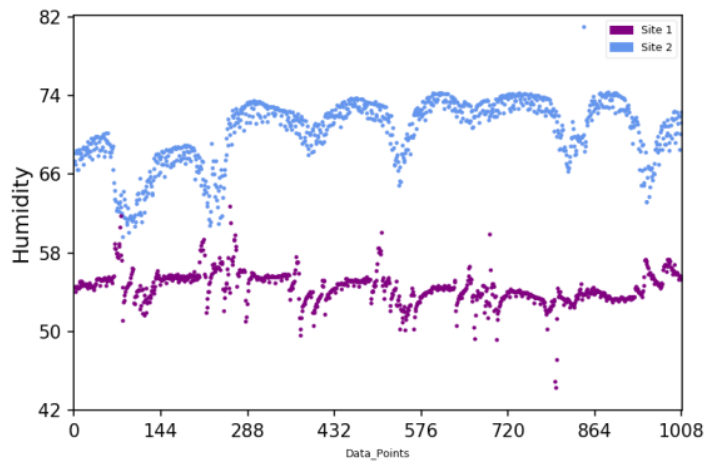

(b)

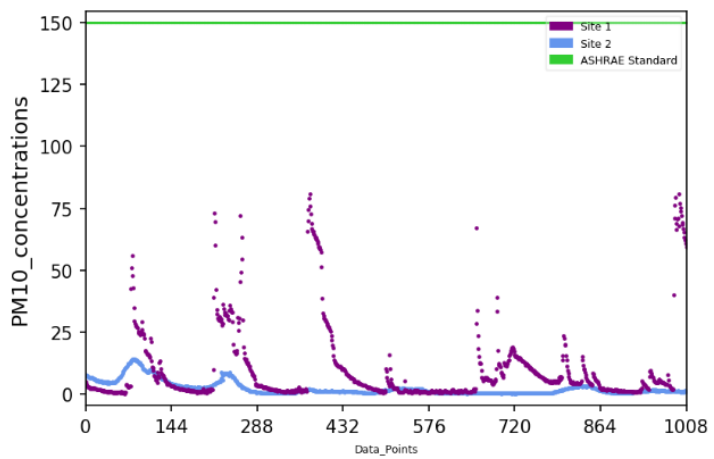

(d)

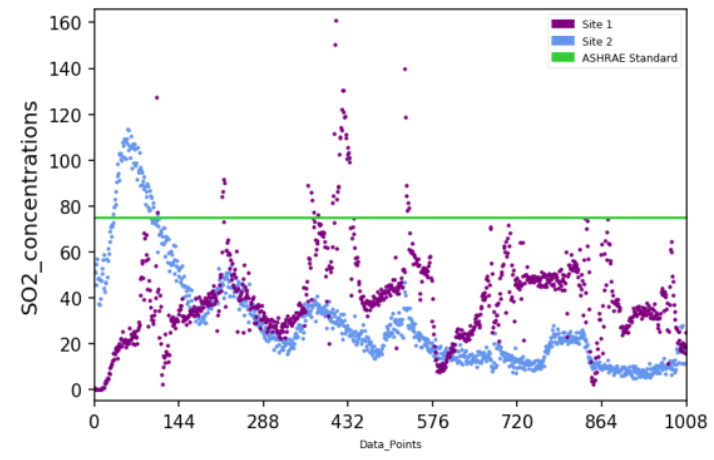

(f)

Figure 4. Cont. 


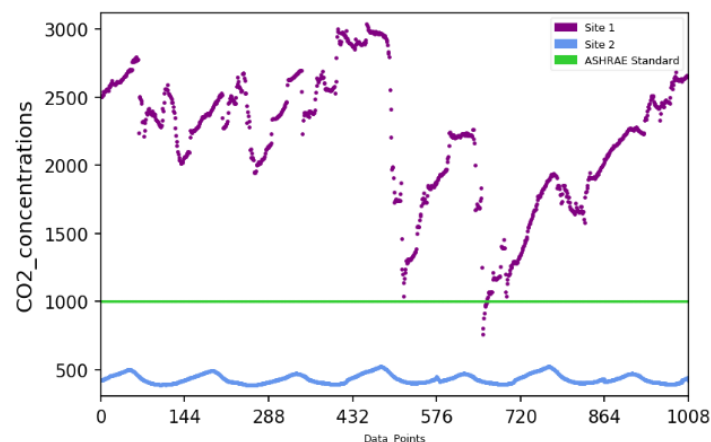

$(\mathrm{g})$

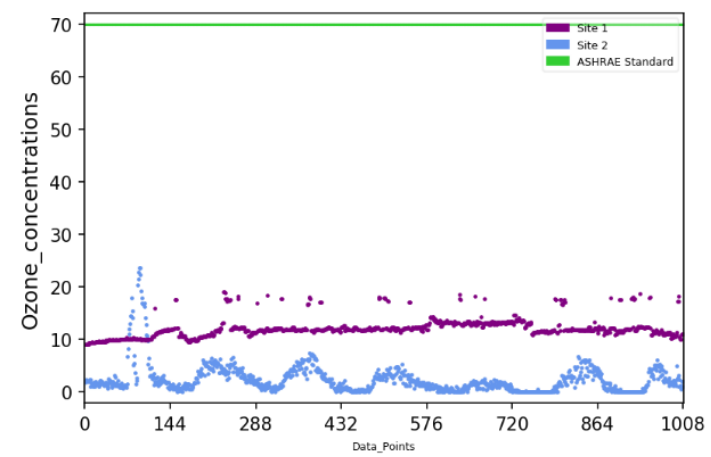

(i)

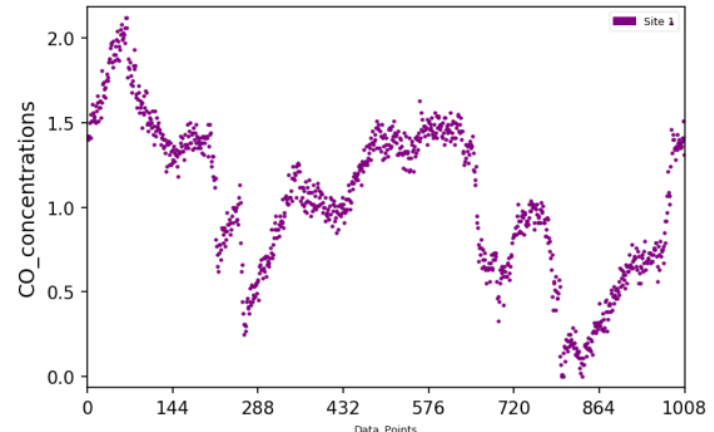

(h)

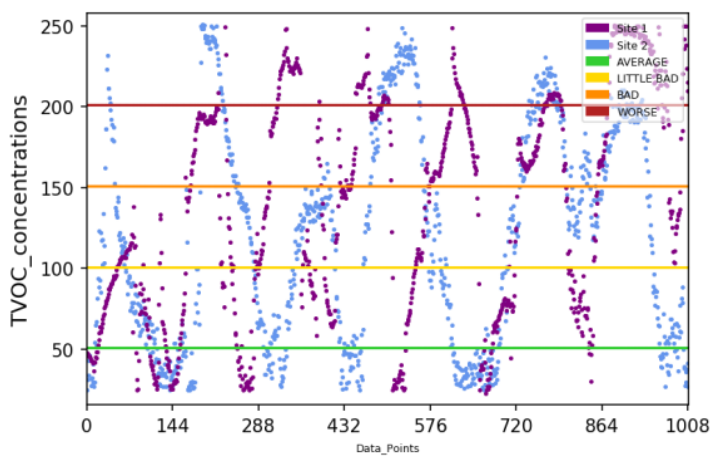

(j)

Figure 4. Seven-day evaluation of indoor environmental parameters monitored at 10-minute intervals (144 observational points a day equating to 1008): (a) temperature, (b) relative humidity, (c) $\mathrm{PM}_{2.5}$, (d) $\mathrm{PM}_{10}$, (e) $\mathrm{NO}_{2}$, (f) $\mathrm{SO}_{2}$, (g) $\mathrm{CO}_{2}$, (h) $\mathrm{CO}$, (i) $\mathrm{O}_{3}$, (j) TVOC.

Quantile-Quantile (Q-Q) plots [62,63] are used to characterize the distribution of measured values at Site 1 and 2. Based on the spread of observational points, the type of distribution can be determined by visually characterizing the data sets with respect to the identity line. If most of the measured points are concentrated along the identity line sharing a similar slope, then the data are normally distributed while a deviation above (high-bias) or below (low-bias) the identity line indicates a skewed distribution. From Figure 5, the $\mathrm{PM}_{2.5}$ and $\mathrm{PM}_{10}$ data are normally distributed with limited deviation from the identity line for low to medium concentrations and exhibit a low-bias towards higher concentrations. For $\mathrm{NO}_{2}$, the observational points are concentrated towards the low and medium spectrum of the data range, while a few points exist away from the distribution for higher concentrations. The slope of TVOC distribution is the most identical to that of the identity line, thereby displaying a high degree of normal distribution while indicating a high closeness in trend between Site 1 and 2. Pollutants such as $\mathrm{SO}_{2}$ and $\mathrm{CO}_{2}$ depict a substantial positive and negative deviation respectively across medium and higher concentrations resulting in a skewed distribution. From lower to medium pollutant levels, $\mathrm{O}_{3}$ has a relatively normal distribution. At higher concentrations, the plot shows a greater positive deviation from the identity line. 


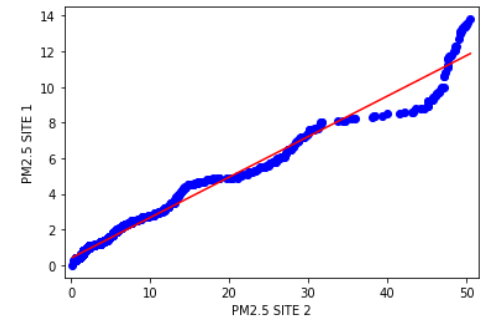

(a)

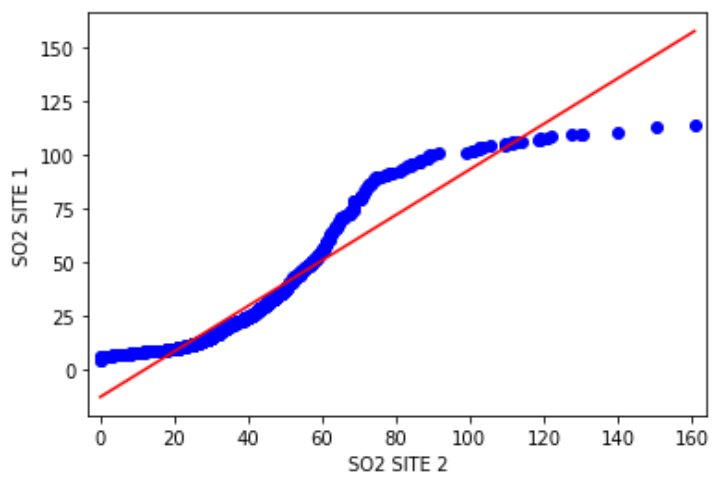

(d)

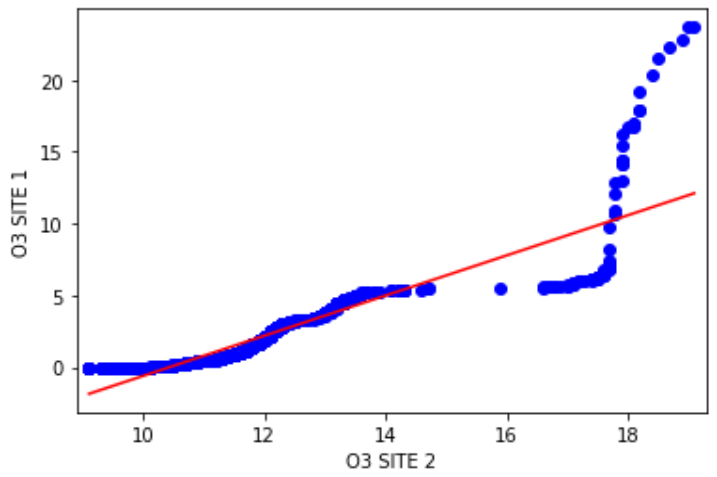

(f)

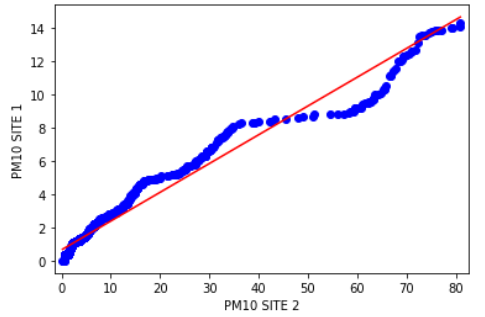

(b)

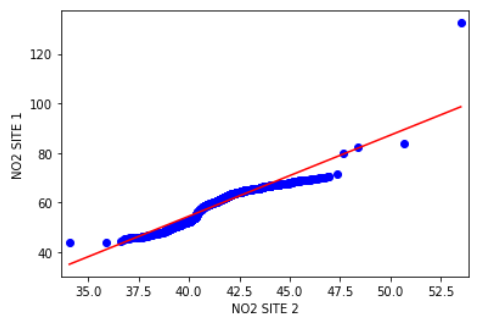

(c)

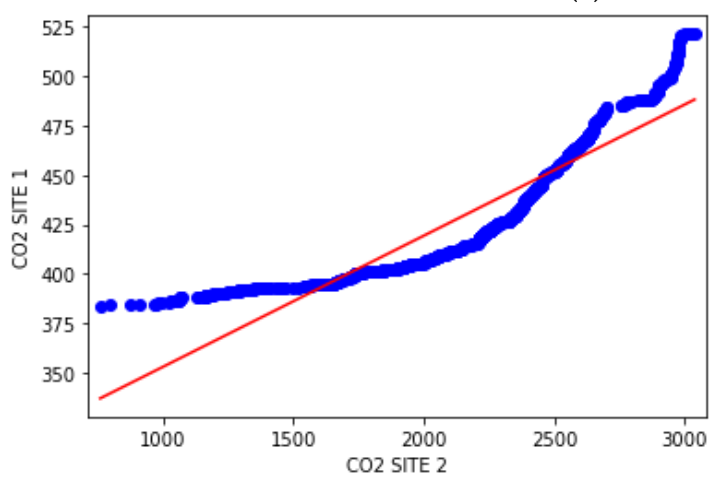

(e)

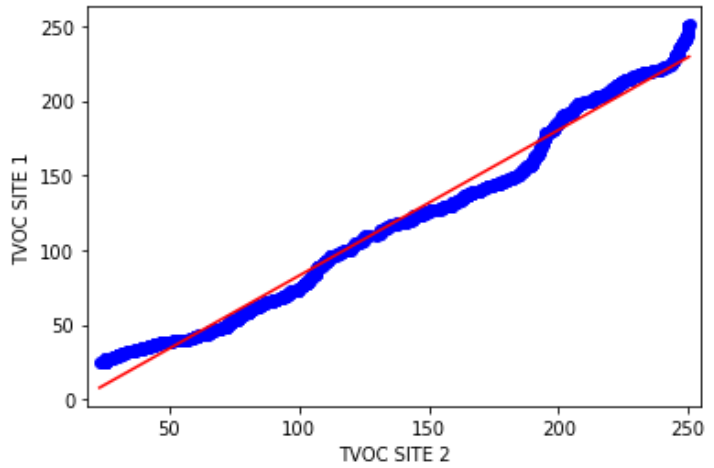

(g)

Figure 5. Quantile-Quantile (Q-Q) plot of indoor pollutants: (a) $\mathrm{PM}_{2.5}$, (b) $\mathrm{PM}_{10}$, (c) $\mathrm{NO}_{2}$, (d) $\mathrm{SO}_{2}$, (e) $\mathrm{CO}_{2}$, (f) $\mathrm{O}_{3}$, and (g) TVOC with an identity line ( $\mathrm{y}=\mathrm{x}$ line which acts as reference to standardize the axis).

The Spearman rank-order analysis was used to estimate the strength of the correlation between two measured parameters by assigning a ranked value (R) between -1 and $1[58,59,64]$. According to Figure 6 , site 2 exhibits a relatively stronger correlation among environmental parameters compared to site 1 . Site 1 shows that $\mathrm{SO}_{2}$ has a strong correlation with $\mathrm{PM}_{2.5}(\mathrm{R}=0.9)$ and $\mathrm{PM}_{10}(\mathrm{R}=0.83)$. This trend can also be found at site 2 among $\mathrm{PM}_{2.5}(\mathrm{R}=0.92)$ and $\mathrm{PM}_{10}(\mathrm{R}=0.9)$. This can be attributed to cooking activities in site 1 and vehicular pollution at site 2 , which both contribute to increasing levels of $\mathrm{SO}_{2}, \mathrm{PM}_{2.5}$, and $\mathrm{PM}_{10}[17,65,66]$. Both sites 1 and 2 have the same degree of negative correlation between $\mathrm{O}_{3}$ and humidity $(\mathrm{R}=-0.78)$. The higher $\mathrm{O}_{3}$ concentrations can be due to increased solar irradiation corresponding to low relative humidity-high temperature surroundings. The temperature values recorded at site 2 shows strong correlations with $\mathrm{O}_{3}(\mathrm{R}=0.78)$, $\mathrm{SO}_{2}(\mathrm{R}=0.8), \mathrm{PM}_{2.5}(\mathrm{R}=0.88)$, and $\mathrm{PM}_{10}(\mathrm{R}=0.9)$. An increase in temperature results in dry air, which might aggregate higher concentrations of $\mathrm{PM}_{2.5}$, and $\mathrm{PM}_{10}$ in a city environment. The relationship between temperature and $\mathrm{O}_{3}, \mathrm{SO}_{2}$, and $\mathrm{PM}_{2.5}$ is similar with the results observed by Mahmoud while exhibiting stronger degrees of correlation [67]. $\mathrm{O}_{3}$ has a strong correlation with $\mathrm{PM}_{2.5}(\mathrm{R}=0.8)$ and $\mathrm{PM}_{10}(\mathrm{R}=0.82)$ at site 2 . There is a moderate correlation between temperature and TVOC $(\mathrm{R}=-0.65)$ at site 1 . Similarly, temperature and TVOC share a moderate correlation $(R=-0.72)$ at site 2 . The similar 
negative correlation between TVOC and temperature within an office space was observed by Otolorin et al. [68]. Site 1 displays a moderate correlation between humidity and $\mathrm{SO}_{2}$ $(\mathrm{R}=-0.62)$, while site 2 exhibits a comparatively stronger correlation $(\mathrm{R}=-0.8) . \mathrm{SO}_{2}$ has the tendency to react with water vapor present in building walls and furniture, which may lead to decreasing concentrations of $\mathrm{SO}_{2}$ as the humidity increases $[12,13,20]$. There is a moderate correlation $(\mathrm{R}=0.58)$ between humidity and $\mathrm{CO}_{2}$ at site 1 and a strong correlation $(\mathrm{R}=0.78)$ at site 2 . Site 1 has a low correlation between $\mathrm{NO}_{2}$ and $\mathrm{CO}_{2}(\mathrm{R}=0.47)$, while site 2 exhibits a relatively stronger correlation $(\mathrm{R}=0.77)$. This might be due to human activities in site 1 and traffic-related pollution at site 2. This correlation between $\mathrm{NO}_{2}$ and $\mathrm{CO}_{2}$ is consistent with the study performed by S.H. Hwang [69]. There is a strong correlation at site 2 between humidity and $\mathrm{NO}_{2}(\mathrm{R}=0.98)$ and a relatively weaker correlation at site 1 $(R=0.45)$. At site 1 there is a moderate correlation between $\mathrm{CO}_{2}$ and $\mathrm{O}_{3}(\mathrm{R}=-0.5)$ while site 2 displays a stronger correlation $(R=-0.9)$ and this may be because of insufficient ventilation $[6,15,70]$. Site 2 registered a moderate correlation between humidity and TVOC $(\mathrm{R}=0.72)$. The $\mathrm{NO}_{2}$ values of site 2 show a moderate correlation with TVOC $(\mathrm{R}=0.73)$ and have a relatively stronger correlation with humidity $(R=0.98)$. This may be attributed to the presence of high-emitting building materials and fuel-burning household appliances at the residential unit $[17,20,66]$.

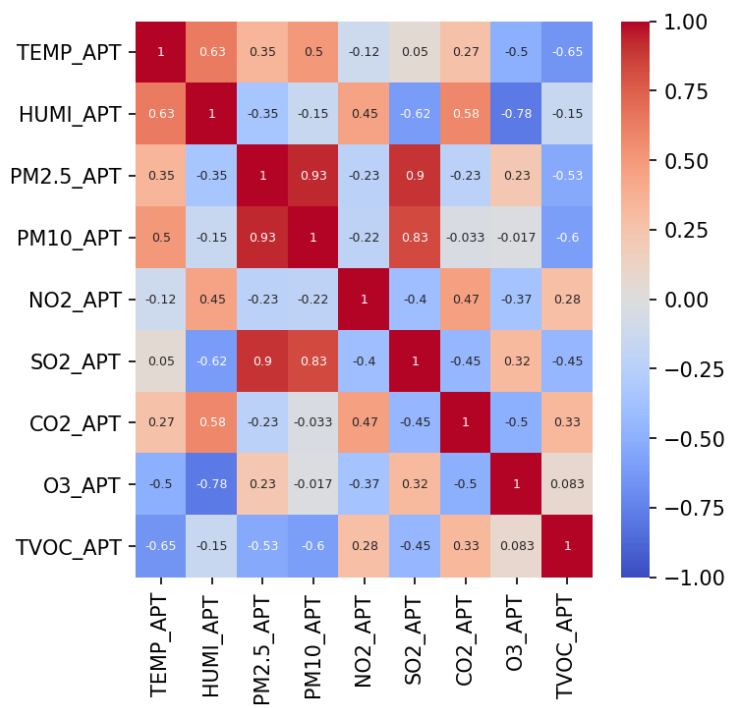

(site 1)

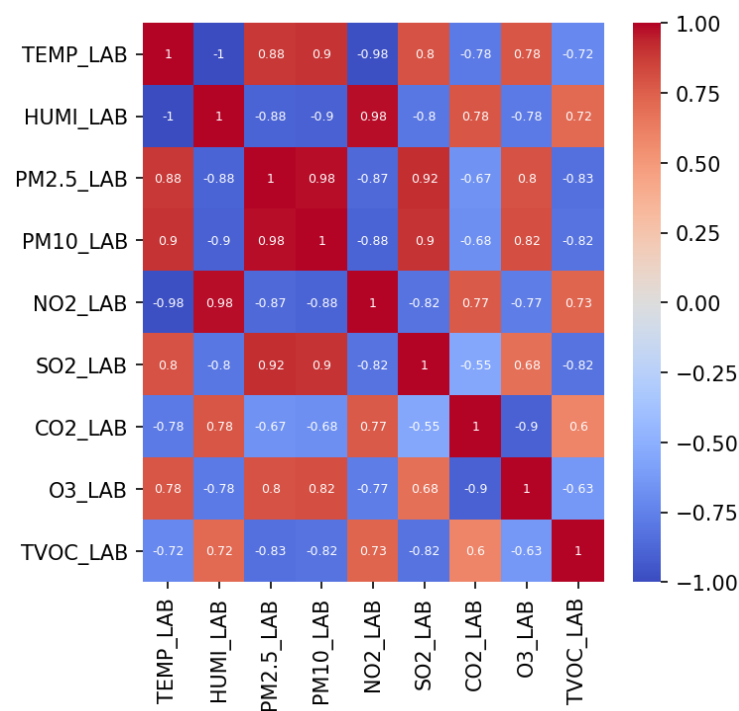

(site 2)

Figure 6. Spearman correlation heat map for indoor environmental parameters at two sites.

\section{Conclusions}

In this paper, a comprehensive environmental monitoring system is presented which detects most of the critical indoor air pollutants. Multiple independent sensors were selected accounting for repeatability, tolerance, and response time. These individual sensor modules were integrated onto a Python-powered Raspberry Pi platform to form a single LCAQS system to measure, analyze, and determine indoor air quality. The multisensor module recorded environmental parameters such as temperature, relative humidity, $\mathrm{PM}_{2.5}, \mathrm{PM}_{10}, \mathrm{NO}_{2}, \mathrm{SO}_{2}, \mathrm{CO}_{2}, \mathrm{CO}, \mathrm{O}_{3}$, and TVOC in real-time at regular 10-min intervals. The logged data was extracted from the LCAQS system and transferred to a computer using an open-source network file transfer application, PuTTY.

It was observed that both $\mathrm{PM}_{2.5}$ and $\mathrm{PM}_{10}$ concentrations were significantly higher in the residential apartment unit (site 1) than at the office space (site 2) while the former recorded maximum values of 50.5 and $80.9 \mu \mathrm{g} / \mathrm{m}^{3}$, respectively. Sites 1 and 2 registered to mean $\mathrm{NO}_{2}$ levels of 41.8 and $60.3 \mathrm{ppb}$, respectively, while site 2 displayed a wider range of observed data between 43.8 and $132 \mathrm{ppb}$. The highest difference in concentration 
levels was observed with $\mathrm{CO}_{2}$, as site 1 (2195 ppm) exhibited $\mathrm{CO}_{2}$ values that were more than five times greater than those of site 2 (432 ppm). Although both sites 1 and 2 displayed comparatively close levels of $\mathrm{SO}_{2}$ at 39.9 and $29.6 \mathrm{ppb}$, respectively, the maximum concentration was observed at site 1 at $161 \mathrm{ppb}$. The mean $\mathrm{O}_{3}$ concentration recorded at site 1 at $12.1 \mathrm{ppb}$ was significantly higher compared to site 2 at $2.37 \mathrm{ppb}$. Both sites registered the same maximum TVOC value of 250, while site 1 displayed a slightly higher average value of 139.2 to that of site 2 at 121.

Spearman rank-order analysis indicates that $\mathrm{PM}_{2.5}$, and $\mathrm{PM}_{10}$ has a strong correlation with $\mathrm{SO}_{2}$ at both site 1 and site 2 . The potential reason for this can be cooking activities in site 1 and vehicular pollution at site 2, which both contribute to increasing levels of $\mathrm{PM}_{2.5}, \mathrm{PM}_{10}$, and $\mathrm{SO}_{2} . \mathrm{O}_{3}$ concentrations at site 2 exhibit a strong correlation with $\mathrm{PM}_{2.5}$ and $\mathrm{PM}_{10} \cdot \mathrm{NO}_{2}$ and $\mathrm{CO}_{2}$ show a relatively stronger correlation at site 1 when compared to site 2 , and this might be due to human activities in site 1 and combustion-related pollution at site 2. Similarly, $\mathrm{NO}_{2}$ and TVOC display moderate correlation at site 2 . There is a moderate correlation between $\mathrm{CO}_{2}$ and $\mathrm{O}_{3}$ at site 1 , while site 2 shows a relatively stronger correlation, and this might be due to insufficient ventilation. The possible effect of an increased number of human occupants on environmental pollutants can be witnessed at site 2, which displays strong temperature and humidity correlation with $\mathrm{O}_{3}, \mathrm{SO}_{2}, \mathrm{PM}_{2.5}$, and $\mathrm{PM}_{10}$ when compared to site 1 .

The constituent sensors of the custom-built LCAQS system utilized in this study rely on factory calibration. It is a challenge to individually calibrate all the sensors owing to limited availability and high cost of calibration equipment in the market for certain pollutants. Owing to the latter, limited efforts have been taken to validate the obtained results with a reference monitor. For future studies, sensor parameters such as such as precision, short and long term drift, and power supply effect can be tested by devising operational rigidity experiments on the sensors to ensure the accuracy of obtained results. Furthermore, the correlation values derived in this paper may need to be examined further to arrive at a conclusive inference. This can be achieved by monitoring air quality for longer periods across different locational settings accounting for varied surroundingrelated influences. Moreover, Principal Component Analysis (PCA) can be undertaken to reduce the multicollinearity of measured parameters. Also, mixed-effect linear regression models are suggested to better study the association between indoor air pollutants and building characteristics.

Supplementary Materials: The supplementary materials are available online at https:/ /www.mdpi. com/2071-1050/13/1/370/s1.

Author Contributions: H.Z.; Sensor Development: H.Z.; Data collection and analysis: H.Z. and V.G.; Writing—Original draft: H.Z. and V.G.; writing—Review and editing: R.S.; supervision: R.S. All authors have read and agreed to the published version of the manuscript.

Funding: This research received no external funding.

Informed Consent Statement: Not applicable.

Data Availability Statement: The data presented in this study are available in supplementary material.

Conflicts of Interest: The authors declare no conflict of interest.

\section{References}

1. ALA. The State of the Air 2020; American Lung Association: Chicago, IL, USA, 2020; pp. 1-57.

2. Pitarma, R.; Marques, G.; Ferreira, B.R. Monitoring Indoor Air Quality for Enhanced Occupational Health. J. Med. Syst. 2017, 41,1-8. [CrossRef] [PubMed]

3. Ritchie, H.; Roser, M. Indoor Air Pollution. Our World Data 2020. Available online: https://ourworldindata.org/indoor-airpollution (accessed on 3 November 2020).

4. Andersson, K. TVOC and health in non-industrial indoor environments report from a Nordic scientific consensus meeting at Langholmen in Stockholm, 1996. Indoor Air 1997, 7, 78-91. [CrossRef] 
5. Saeki, Y.; Kadonosono, K.; Uchio, E. Clinical and allergological analysis of ocular manifestations of sick building syndrome. Clin. Ophthalmol. 2017, 11, 517-522. [CrossRef] [PubMed]

6. Ahmed Abdul-Wahab, S.A.; En, S.C.F.; Elkamel, A.; Ahmadi, L.; Yetilmezsoy, K. A review of standards and guidelines set by international bodies for the parameters of indoor air quality. Atmos. Pollut. Res. 2015, 6, 751-767. [CrossRef]

7. Menzies, D.; Bourbeau, J. Building-Related Illnesses. N. Engl. J. Med. 1997, 337, 1524-1531. [CrossRef] [PubMed]

8. Zhang, H.; Srinivasan, R. A systematic review of air quality sensors, guidelines, and measurement studies for indoor air quality management. Sustainability 2020, 12, 9045. [CrossRef]

9. Wagner, J.G.; Kamal, A.S.; Morishita, M.; Dvonch, J.T.; Harkema, J.R.; Rohr, A.C. PM 2.5 -Induced cardiovascular dysregulation in rats is associated with elemental carbon and temperature-resolved carbon subfractions. Part. Fibre Toxicol. 2014, 11, 25. [CrossRef]

10. EPA. A Standardized EPA Protocol for Characterizing Indoor Air Quality in Large Office Buildings; EPA: Washington, DC, USA, 2016.

11. Branco, P.T.B.S.; Nunes, R.A.O.; Alvim-Ferraz, M.C.M.; Martins, F.G.; Sousa, S.I.V. Children's exposure to indoor air in urban nurseries-Part II: Gaseous pollutants' assessment. Environ. Res. 2015, 142, 662-670. [CrossRef]

12. NAAQS. Primary National Ambient Air Quality Standard (NAAQS) for Sulfur Dioxide. Available online: https://www.epa. gov/so2-pollution/ primary-national-ambient-air-quality-standard-naaqs-sulfur-dioxide (accessed on 26 July 2019).

13. Spengler, J.D.; Ferris, B.G.; Dockery, D.W.; Speizer, F.E. Sulfur Dioxide and Nitrogen Dioxide Levels Inside and Outside Homes and the Implications on Health Effects Research. Environ. Sci. Technol. 1979, 13, 1276-1280. [CrossRef]

14. Johnson, D.L.; Lynch, R.A.; Floyd, E.L.; Wang, J.; Bartels, J.N. Indoor air quality in classrooms: Environmental measures and effective ventilation rate modeling in urban elementary schools. Build. Environ. 2018, 136, 185-197. [CrossRef]

15. Madureira, J.; Paciência, I.; Rufo, J.; Severo, M.; Ramos, E.; Barros, H.; de Oliveira Fernandez, E. Source apportionment of CO 2 , $\mathrm{PM}_{10}$ and VOCs levels and health risk assessment in naturally ventilated primary schools in Porto, Portugal. Build. Environ. 2016, 96, 198-205. [CrossRef]

16. Seltzer, J.M. Building-related illnesses. J. Allergy Clin. Immunol. 1994, 94, 351-361. [CrossRef] [PubMed]

17. Civan, M.Y.; Elbir, T.; Seyfioglu, R.; Kuntasal, Ö.O.; Bayram, A.; Doğan, G.; Yurdakul, S.; Andiç, Ö.; Müezzinoğlu, A.; Sofuoglu, S.C.; et al. Spatial and temporal variations in atmospheric $\mathrm{VOC}_{\mathrm{s}}, \mathrm{NO}_{2}, \mathrm{SO}_{2}$, and $\mathrm{O}_{3}$ concentrations at a heavily industrialized region in Western Turkey, and assessment of the carcinogenic risk levels of benzene. Atmos. Environ. 2015, 103, 102-113. [CrossRef]

18. EPA. Building Air Quality—A Guide for Building Owners and Facility Managers; EPA-402-F-91-102; EPA: Washington, DC, USA, 1991; pp. 1-228.

19. WHO. WHO Guidelines for Indoor Air Quality: Selected Pollutants; WHO: Copenhagen, Denmark, 2010 ; Volume 35.

20. Gvozdić, V.; Kovač-Andrić, E.; Brana, J. Influence of Meteorological Factors $\mathrm{NO}_{2}, \mathrm{SO}_{2}, \mathrm{CO}$ and $\mathrm{PM}_{10}$ on the Concentration of $\mathrm{O}_{3}$ in the Urban Atmosphere of Eastern Croatia. Environ. Model. Assess. 2011, 16, 491-501. [CrossRef]

21. Yang, J.; Seo, J.H.; Jeong, N.N.; Sohn, J.R. Effects of Legal Regulation on Indoor Air Quality in Facilities for Sensitive PopulationsA Field Study in Seoul, Korea. Environ. Manag. 2019, 64, 344-352. [CrossRef]

22. Fishbain, B.; Lerner, U.; Castell, N.; Cole-Hunter, T.; Popoola, O.; Broday, D.M.; Martinez Iniquez, T.; Nieuwenhuijsen, M.; Jovasevic-Stojanovic, M.; Topalovic, D.; et al. An evaluation tool kit of air quality micro-sensing units. Sci. Total Environ. 2017, 575, 639-648. [CrossRef]

23. Munir, S.; Mayfield, M.; Coca, D.; Jubb, S.A.; Osammor, O. Analysing the performance of low-cost air quality sensors, their drivers, relative benefits and calibration in cities-A case study in Sheffield. Environ. Monit. Assess. 2019, 191. [CrossRef]

24. Clements, A.L.; Griswold, W.G.; Abhijit, R.S.; Johnston, J.E.; Herting, M.M.; Thorson, J.; Collier-Oxandale, A.; Hannigan, M. Low-Cost air quality monitoring tools: From research to practice (A workshop summary). Sensors 2017, 17, 2478. [CrossRef]

25. Williams, R.; Kilaru, V.J.; Snyder, E.G.; Kaufman, A.; Dye, T.; Rutter, A.; Russel, A.; Hafner, H. Air Sensor Guidebook; National Exposure Research Laboratory: Research Triangle Park, NC, USA, 2014. [CrossRef]

26. Williams, R. Tools and Resources Webinar: Low Cost Air Quality Sensors; EPA: Washington, DC, USA, 2019.

27. Morawska, L.; Thai, P.K.; Liu, X.; Asumadu-Sakyi, A.; Ayoko, G.; Bartonova, A.; Bedini, A.; Chai, F.; Christensen, B.; Dunbabin, M.; et al. Applications of low-cost sensing technologies for air quality monitoring and exposure assessment: How far have they gone? Environ. Int. 2018, 116, 286-299. [CrossRef]

28. Polidori, A.; Papapostolou, V.; Zhang, H. Laboratory Evaluation of Low-Cost Air Quality Sensors; South Coast AQMD: Diamond Bar, CA, USA, 2016.

29. AQ-SPEC. Laboratory Evaluation Air Quality Egg 2018 Model; South Coast AQMD: Diamond Bar, CA, USA, 2018.

30. Giusto, E.; Gandino, F.; Greco, M.L.; Grosso, M.; Montrucchio, B.; Rinaudo, S. An investigation on pervasive technologies for IoT-based thermal monitoring. Sensors 2019, 19, 663. [CrossRef]

31. Thompson, J.E. Crowd-Sourced air quality studies: A review of the literature \& portable sensors. Trends Environ. Anal. Chem. 2016, 11, 23-34. [CrossRef]

32. Abraham, S.; Li, X. A cost-effective wireless sensor network system for indoor air quality monitoring applications. Procedia Comput. Sci. 2014, 34, 165-171. [CrossRef]

33. Zhou, M.; Abdulghani, A.M.; Imran, M.A.; Abbasi, Q.H. Internet of Things (IoT) Enabled Smart Indoor Air Quality Monitoring System. ACM Int. Conf. Proc. Ser. 2020, 89-93. [CrossRef]

34. Mohd Pu'ad, M.F.; Gunawan, T.S.; Kartiwi, M.; Janin, Z. Performance evaluation of portable air quality measurement system using raspberry Pi for remote monitoring. Indones. J. Electr. Eng. Comput. Sci. 2019, 17, 564-574. [CrossRef] 
35. Kumar, S.; Jasuja, A. Air quality monitoring system based on IoT using Raspberry Pi. In Proceedings of the 2017 IEEE International Conference on Computing, Communication and Automation (ICCCA), Greater Noida, India, 5-6 May 2017; pp. 1341-1346. [CrossRef]

36. Saha, A.K.; Sircar, S.; Chatterjee, P.; Dutta, S.; Mitra, A.; Chatterjee, A.; Chattopadhyay, S.P.; Saha, H.N. A raspberry Pi controlled cloud based air and sound pollution monitoring system with temperature and humidity sensing. In Proceedings of the 2018 IEEE 8th Annual Computing and Communication Workshop and Conference (CCWC), Las Vegas, NV, USA, 8-10 January 2018; pp. 607-611. [CrossRef]

37. Kiruthika, R.; Umamakeswari, A. Low cost pollution control and air quality monitoring system using Raspberry Pi for Internet of Things. In Proceedings of the 2017 International Conference on Energy, Communication, Data Analytics and Soft Compututing (ICECDS), Chennai, India, 1-2 August 2017; pp. 2319-2326. [CrossRef]

38. Alkandari, A.A.; Moein, S. Implementation of monitoring system for air quality using raspberry Pi: Experimental study. Indones. J. Electr. Eng. Comput. Sci. 2018, 10, 43-49. [CrossRef]

39. Ali, A.S.; Zanzinger, Z.; Debose, D.; Stephens, B. Open Source Building Science Sensors (OSBSS): A low-cost Arduino-based platform for long-term indoor environmental data collection. Build. Environ. 2016, 100, 114-126. [CrossRef]

40. Parkinson, T.; Parkinson, A.; de Dear, R. Continuous IEQ monitoring system: Performance specifications and thermal comfort classification. Build. Environ. 2019, 149, 241-252. [CrossRef]

41. Mejía, J.F.; Choy, S.L.; Mengersen, K.; Morawska, L. Methodology for assessing exposure and impacts of air pollutants in school children: Data collection, analysis and health effects-A literature review. Atmos. Environ. 2011, 45, 813-823. [CrossRef]

42. WHO. Risk of Bias Assesssment Instrument for Systematic; WHO Regional Office for Europe: Copenhagen, Denmark, 2020.

43. Raspberry, P. Raspberry Pi 3 Model B+ Datasheet; Raspberry Pi Ltd.: Milton, UK, 2016; p. 5.

44. DHT22. Digital-Output Relative Humidity E Temperature Sensor/Module AM2303, DHT22, Datasheet; Aosong Electron Co, Ltd.: Guangzhou, China, 2015. Available online: https://www.electroschematics.com/wp-content/uploads/2015/02/DHT22datasheet.pdf (accessed on 20 June 2020).

45. Nova Fitness Co., Ltd. $\mathrm{PM}_{2.5}$ L. Laser $\mathrm{PM}_{2.5}$ Sensor. Available online: https://cdn-reichelt.de/documents/datenblatt/X200 /SDS011-DATASHEET.pdf (accessed on 31 July 2019).

46. SPEC Sensors. DGS-NO2 986-042, Digital Gas Sensor-Ozone. Available online: https://media.digikey.com/pdf/DataSheets/ SPECSensorsPDFs/968-043_9-6-17.pdf (accessed on 25 July 2019).

47. SPEC Sensors. DGS-SO2 986-042, Digital Gas Sensor-Ozone. Available online: https://www.spec-sensors.com/wp-content/ uploads /2017/01/DGS-SO2-968-038.pdf (accessed on 25 July 2019).

48. CO2Meter. K-30.K-30. Available online: https://img.ozdisan.com/ETicaret_Dosya/456729_1584920.PDF (accessed on 30 July 2019).

49. Digi-Key Electronics. 968-034 D-C, Digital Gas Sensor-Carbon Monoxide. Available online: https://www.digikey.com/en/ products/detail/spec-sensors-1lc/968-034/6676880 (accessed on 26 July 2019).

50. SPEC Sensors. DGS-O3, Digital Gas Sensor-Ozone. Available online: https://www.spec-sensors.com/wp-content/uploads/20 17/01/DGS-O3-968-042_9-6-17.pdf (accessed on 25 July 2019).

51. Ohmetch.io. UTHING::VOCTM ${ }^{\mathrm{TM}}$ Air-Quality USB Sensor Dongle. Available online: https://ohmtech.io/products/uthingvoc/ \#specifications (accessed on 10 June 2019).

52. Mitsubishi Electric. TECHNICAL \& SERVICE MANUAL. PEA-A18AA. PEA-A18AA. Available online: https://www. mitsubishitechinfo.ca/sites/default/files/PEA-A12-18AA4_Service_0.pdf (accessed on 28 June 2020).

53. EPA. What is a MERV rating? Indoor Air Quality (IAQ). Available online: https://www.epa.gov/indoor-air-quality-iaq/whatmerv-rating-1 (accessed on 5 June 2020).

54. Goodman Air Conditioning and Health. GOODMAN GSX130481 4-tons 2 Ton Central Air Conditioner Air Handler Unit (Model AWUF24051BA). Available online: https:/ / www.goodmanmfg.com/products/air-conditioners/13-seer-gsx13 (accessed on 8 June 2020).

55. ANSI/ASHRAE. ANSI/ASHRAE Standard 62.1-2019, Ventilation for Acceptable Indoor Air Quality; American Society of Heating, Refrigerating and Air-Conditioning Engineers: Atlanta, GA, USA, 2019.

56. WHO. Methods for Monitoring Indoor Air Quality in Schools; WHO: Bonn, Germany, 2011.

57. Meier, R.; Schindler, C.; Eeftens, M.; Aguilera, I.; Ducret-Stich, R.E.; Ineichen, A.; Davey, M.; Phuleria, H.C.; Probst-Hensch, N.; Tsai, M.-Y.; et al. Modeling indoor air pollution of outdoor origin in homes of SAPALDIA subjects in Switzerland. Environ. Int. 2015, 82, 85-91. [CrossRef]

58. Majd, E.; McCormack, M.; Davis, M.; Curriero, F.; Berman, J.; Connolly, F.; Leaf, P.; Rule, A.; Green, T.; Clemons-Erby, D.; et al. Indoor air quality in inner-city schools and its associations with building characteristics and environmental factors. Environ. Res. 2019, 170, 83-91. [CrossRef]

59. Raysoni, A.U.; Stock, T.H.; Sarnat, J.A.; Chavez, M.C.; Sarnat, S.E.; Montoya, T.; Holguin, F.; Li, W.-W. Evaluation of VOC concentrations in indoor and outdoor microenvironments at near-road schools. Environ. Pollut. 2017, 231, 681-693. [CrossRef] [PubMed]

60. Sunyer, J.; Esnaola, M.; Alvarez-Pedrerol, M.; Forns, J.; Rivas, I.; López-Vicente, M.; Suades-Gonzalez, E.; Foraster, M.; GarciaEsteban, R.; Basagana, X.; et al. Association between traffic-related air pollution in schools and cognitive development in primary school children: A prospective cohort study. PLoS Med. 2015, 12, e1001792. [CrossRef] [PubMed] 
61. Krzyzanowski, M.; Cohen, A. Update of WHO air quality guidelines. Air Qual. Atmos. Health 2008, 1, 7-13. [CrossRef]

62. Zurbenko, I.G. Detecting and tracking changes in ozone air quality. Air Waste 1994, 44, 1089-1092. [CrossRef]

63. Seangkiatiyuth, K.; Surapipith, V.; Tantrakarnapa, K.; Lothongkum, A. Application of the AERMOD modeling system for environmental impact assessment of $\mathrm{NO}_{2}$ emissions from a cement complex. J. Environ. Sci. 2011, 23, 931-940. [CrossRef]

64. Hwang, S.H.; Roh, J.; Park, W.M. Evaluation of $\mathrm{PM}_{10}, \mathrm{CO}_{2}$, airborne bacteria, TVOCs, and formaldehyde in facilities for susceptible populations in South Korea. Environ. Pollut. 2018, 242, 700-708. [CrossRef]

65. Scibor, M. Are we safe inside? Indoor air quality in relation to outdoor concentration of $\mathrm{PM}_{10}$ and $\mathrm{PM}_{2.5}$ and to characteristics of homes. Sustain. Cities Soc. 2019, 48, 101537. [CrossRef]

66. Chock, D.P.; Winkler, S.L.; Chen, C. A study of the association between daily mortality and ambient air pollutant concentrations in Pittsburgh, Pennsylvania. J. Air Waste Manag. Assoc. 2000, 50, 1481-1500. [CrossRef]

67. El-Sharkawy, M.F. Assessment of Ambient Air Quality Level at Different Areas inside Dammam University, Case Study. Met. Environ. Arid Land Agric. Sci. 2013, 142, 1-28. [CrossRef]

68. Adebayo, O.J.; Abosede, O.O.; Sunday, F.B.; Ayooluwa, A.A.; Adetayo, A.J.; Ademola, S.J.; Alaba, A.F. Indoor air quality level of total volatile organic compounds (TVOCs) in a university offices. Int. J. Civ. Eng. Technol. 2018, 9, 2872-2882.

69. Hwang, S.H.; Park, W.M. Indoor air concentrations of carbon dioxide $\left(\mathrm{CO}_{2}\right)$, nitrogen dioxide $\left(\mathrm{NO}_{2}\right)$, and ozone $\left(\mathrm{O}_{3}\right)$ in multiple healthcare facilities. Environ. Geochem. Health 2020, 42, 1487-1496. [CrossRef] [PubMed]

70. Dai, X.; Liu, J.; Zhang, X. Monte Carlo simulation to control indoor pollutants from indoor and outdoor sources for residential buildings in Tianjin, China. Build. Environ. 2019, 165, 106376. [CrossRef] 